\title{
Controlling the Shape of Filamentous Cells of Escherichia Coli
}

\author{
Shoji Takeuchi ${ }^{1,2}$, Willow R. DiLuzio ${ }^{1}$, Douglas B. Weibel ${ }^{1}$, and George M. Whitesides ${ }^{1}$, \\ 1 Department of Chemistry and Chemical Biology, Harvard University 12 Oxford St., Cambridge, MA 02138, \\ U.S.A. \\ 2Institute of Industrial Science, The University of TOKYO, 4-6-1 Komaba, Meguro-ku, Tokyo 153-8505, \\ JAPAN
}

\section{Abstract}

This paper describes a technique for growing filamentous cells of $E$. coli with defined shapes, including: crescents, zigzags, sinusoids, and spirals. The procedure begins with the fabrication of embossed microchambers in agarose. Cells are trapped in the chambers by placing a flat, flexible "ceiling" - either a slab of agarose or poly(dimethylsiloxane) — against an agarose mold on which a suspension of cells has been added; the use of agarose keeps cells hydrated and allows nutrients to diffuse into the chambers. Cells grown in microchambers in the presence of cephalexin grow into a multinucleate, non-septate, filamentous phenotype and adopt the shape of the microchambers. The resulting cells are motile and can be released by removing the "ceiling"from the agarose microchambers and rinsing the cells into solution.

This paper describes a technique for controlling the shape of filamentous cells of Escherichia coli. We seeded agarose microchambers with single cells of $E$. coli, and found that filamentous cells grown in the spatial confinement of microchambers both adopted the shape of the chamber and retained that shape when released. Cells with different shapes - crescents, zigzags, sinusoids, and spirals - were motile, but the shape markedly affected the swimming behavior of the cells. This work demonstrates a technique for the fabrication of cells of bacteria with defined shapes without genetic manipulation. These shaped, filamentous cells should be useful for studying: i "optimal" shapes for self-propelled, microstructures swimming at low Reynolds numbers; ii) relationships between the shape of cells and their behavior while swimming; and iii) relationships between the mechanical stress of confinement during growth and the resulting distribution of proteins that are responsible for the elongation, division, and shape of cells of bacteria.

Individual cells of $E$. coli are rod-shaped and are approximately $800 \mathrm{~nm}$ wide and $2.5 \mu \mathrm{m}$ long. Filamentous cells of $E$. coli are long, multi-nucleoid, and form when normal cells elongate and replicate their DNA, but do not septate and divide. ${ }^{1}$ These elongated cells act as if they were "normal" cells - they express genes normally ${ }^{2}$ and continue to synthesize flagella. ${ }^{3}$ The absence of a septum (the dividing wall that forms prior to cell division) allows small molecules to diffuse the length of the long, continuous interior of the cell. ${ }^{4}$ Filamentous cells of $E$. coli have been used to study swimming and chemotaxis, $3-5$ cell growth and division, $2,6,7$ the coordination of flagellar motors, 4,5 and the distribution and partitioning of new peptidoglycan during the expansion of the cell wall and formation of the septum. 6

\footnotetext{
*Author to whom correspondence should be addressed Telephone Number: (617) 4959430 Fax Number: (617) 4959852 Email Address: gwhitesides@gmwgroup.harvard.edu

Supporting Information Available:Materials and methods for fabricating agarose microchambers, conditions for growing bacteria, techniques for imaging and image analysis, and supporting videos are included. This materials is available free of charge via the Internet at http://pubs.acs.org.
} 
E. coli cells move through solution in approximately straight "runs"and redirecting "tumbles". Cells swim by rotating several helical flagella; each flagellum is $20 \mathrm{~nm}$ wide and $10 \mu \mathrm{m}$ long. 8 The rotating flagella (counter-clockwise) of $E$. coli exert a forward thrust on the body of the cell that propels the cell through the solution; the torque produced on the body of the cell causes the cell to rotate. ${ }^{8}$ For normal cell of $E$. coli, the axis of rotation is colinear with the flagellar bundle. ${ }^{9}$ Cells can effectively translate through a solution if the flagella generate sufficient thrust to overcome the viscous drag on the body of the cell (which depends on the shape of the cell). The swimming speed of normal cells of $E$. coli is approximately $20 \mu \mathrm{m} / \mathrm{s}$ and the rotational speed is approximately $10 \mathrm{~Hz} .{ }^{9}$ Filamentous cells of $E$. coli have been shown to swim at approximately $11 \mu \mathrm{m} / \mathrm{s}$ and to alternately "run" and "stop" in solution instead of "run"and "tumble". 3

Penicillin binding proteins are responsible for the polymerization of the peptidoglycan layer in the cell wall of bacteria and are important in regulating the shape of cells. The filamentous phenotype has been generated by inhibition, mutation, or deletion of penicillin-binding protein 3 (PBP3, E.C. 3.4.16.4; also referred to as FtsI). ${ }^{6,7,10}$ PBP3 is responsible for cross-linking the peptidoglycan wall in the division septum of $E$. coli and can be inhibited by $\beta$-lactam antibiotics, such as cephalexin. ${ }^{7}$ Deleting one or more of the other eight penicillin binding proteins results in cells with a filamentous, spherical, or branched shape. ${ }^{1-13}$ Mutations in other proteins involved in cell scaffolding (Mre and Mbl proteins) and cell division (FtsZ and Min proteins) also result in cells with altered morphologies. ${ }^{14-17}$

Poly(dimethylsiloxane)(PDMS) microchambers have been used to effectively confine and study single proteins. ${ }^{18,19}$ Rondelez et al. confined single molecules of F1-ATPase by pressing a PDMS stamp with embossed microchambers against a flat glass plate on which an aqueous suspension of motor proteins had been deposited. When the distance between the chambers was only a few microns, motor proteins (size range 10-1000 $\mathrm{nm}$ ) were largely captured in the chambers; very few proteins were trapped between the bottom of the PDMS stamp and the glass slide. ${ }^{18}$ Here, we have used a similar approach — placing a flexible film of PDMS against a mold containing a droplet of liquid — to trap bacterial cells in an array of microchambers in agarose. The use of agarose microchambers allowed us to grow cells in an environment in which nutrients continuously diffused into the chambers. Figure 1 summarizes the method we used to control the shape of filamentous cells.

We prepared agarose chambers by replica molding against a master that contained features of photoresist (SU8, MicroChem Corp.) in bas relief fabricated using photolithography or by replica molding against a poly(dimethylsiloxane) (PDMS) stamp made by soft lithography. 20 Hot, liquid media ( $1 \%$ tryptone, $0.5 \%$ sodium chloride, $0.05 \% \mathrm{BSA}$, and $20 \mu \mathrm{g} / \mathrm{mL}$ cephalexin, $\left.65^{\circ} \mathrm{C}\right)$ containing agarose $(2 \%, \mathrm{w} / \mathrm{v})$ was poured on the masters and allowed to gel for at least $15 \mathrm{~min}$. The slab of agarose was peeled away from the master and a suspension of $E$. coli cells $\left(5 \mu \mathrm{L}, \sim 10^{4}\right.$ cells $/ \mu \mathrm{L}$, strain AW $\left.405^{21}\right)$ was placed on the agarose substrate; cells were grown in solution at $31-33{ }^{\circ} \mathrm{C}$ on a rotary shaker $(150 \mathrm{rpm})$ for $2 \mathrm{hr}$ by diluting a saturated liquid culture $1: 100$ into $5 \mathrm{~mL}$ of fresh TB-broth (1\% tryptone, $0.5 \%$ sodium chloride, $\mathrm{pH}$ 7.0). To confine cells, a "ceiling"consisting of a flat slab (1-2 mm thick) of agarose ( $0.5 \%$ agarose $\mathrm{w} / \mathrm{v}$ in $1 \%$ tryptone, $0.5 \%$ sodium chloride, $0.05 \%$ BSA, and $20 \mu \mathrm{g} / \mathrm{mL}$ cephalexin) or a film of PDMS (150 $\mu \mathrm{m}$ thick), was placed on top of the agarose chambers. We adjusted the concentration of cells to avoid trapping more than one cell in each chamber. Cells confined in agarose microchambers were grown at $31-33^{\circ} \mathrm{C}$ in an incubator, or on a temperature-controlled microscope stage for 2-3 hr (see Figure 1c). The presence of cephalexin - an antibiotic that inhibits PBP3 - produced the filamentous phenotype. ${ }^{7}$

We observed the growth of filamentous cells using phase-contrast microscopy on a temperature-controlled microscope stage set at $32^{\circ} \mathrm{C}$. Over a period of $2 \mathrm{hr}$, cells that were 
confined in donut-shaped wells grew into filamentous cells that had a characteristic, circular shape (Figure 2a). We measured the growth of 14 cells in the same array of chambers and found that the rates of growth were similar, and were exponential (Figure 2b); the starting length of the cells was $4.2 \pm 2.1 \mu \mathrm{m}$. The "doubling-time" 22 — here the time required for cells to double in length — of these cells was $41 \pm 4 \mathrm{~min}$. The exponential growth of cells in these experiments demonstrates that sufficient nutrients for growth are available to cells confined in microchambers. Using agarose microchambers with different shapes, we grew filamentous cells into circular, sinusoidal, and zigzag shapes (Figure $2 \mathrm{~d}$ ). The efficiency of confinement - the percentage of cells confined in chambers relative to the total number of cells observed on the entire surface of the mold - was calculated for $>2000$ cells using an array of donutshaped microchambers (height $=2.2 \mu \mathrm{m}$, diameter $=8 \mu \mathrm{m}$, width of channel $=3 \mu \mathrm{m}$, pitch $=10$ $\mu \mathrm{m})$; Figure $1 \mathrm{~b}$ shows a small area of this array of chambers. The efficiency of confinement for this pattern was $93 \%$. The remaining $7 \%$ of cells grew on regions of the agarose between the embossed chambers. When cells were grown in chambers with a zigzag geometry, such as those shown in Figure 2e, the cells initially grew straight and then adopted the shape of the pattern; the cells eventually grew out of the chamber. This result suggests to us that cells sense the mechanical stress imposed by the chamber and grow into a shape that minimizes the mechanical stress they experience.

We released filamentous cells from microchambers by removing the agarose or PDMS ceiling, and rinsing the agarose chambers with growth media (TB broth, $0.05 \% \mathrm{BSA}$, and $20 \mu \mathrm{g} / \mathrm{mL}$ cephalexin) or placing a flow cell above the agarose chamber that consisted of a PDMS spacer and a glass slide. All of the filamentous cells grown in confinement in agarose microchambers maintained their shape when they were released into solution.

Filamentous cells of $E$. coli grown in circular microchambers formed crescents or spirals; the shape of the cells depended on the length of time they were left in the chambers and the height of the chambers. When cells were grown in chambers that were 1.3-1.5 $\mu \mathrm{m}$ tall with an outer radius of $10 \mu \mathrm{m}$ for $<2 \mathrm{hr}$, crescent-shaped filamentous cells formed. Figure $3 \mathrm{a}$ shows the distribution of the lengths of crescent-shaped cells grown for $1.5 \mathrm{hr}$. The variation in the length of cells during growth in microchambers was primarily due to the difference in the initial length of cells; the rate of growth of individual cells was similar (Figure 2b). When cells were grown in chambers that were $2.2-2.5 \mu \mathrm{m}$ tall with an outer radius of $10 \mu \mathrm{m}$ for $>2 \mathrm{hr}$, the filamentous cells wound around the chambers and formed spiral shapes ("springs") when released (Figure $3 \mathrm{c})$. Figure $3 \mathrm{~b}$ shows the distribution of the diameter of crescent-shaped or spiral-shaped filamentous cells after release into solution; the coefficient of the variation (C.V.) in the diameter was approximately $8 \%$.

We released cells from agarose microchambers into growth media ( $1 \%$ tryptone, $0.5 \%$ sodium chloride, and $0.05 \%$ BSA) with and without cephalexin $(50 \mu \mathrm{g} / \mathrm{mL})$, and continued to observe their growth in solution. When filamentous cells with planar, circular shapes were grown in media containing cephalexin, the cells grew larger and retained their circular shape (Figure 4a). When spiral-shaped cells were grown in media containing cephalexin, the cells retained a spiral shape, but the pitch of the spiral expanded as a function of time (Figure 4b). It appears that during the growth of shaped, filamentous cells, new peptidoglycan is inserted along the entire length of the cell. ${ }^{6}$ Spiral, filamentous cells with a pitch of several microns would be impossible to grow by confinement in agarose chambers alone; additional growth of cells in solution after their release allowed us to modify further the shapes of filamentous cells.

Circular cells that were released from microchambers into growth media that did not contain cephalexin began dividing at what appeared to be random positions along the cells. Figure 4c shows a crescent-shaped cell dividing. After several hours of growth in media that did not 
contain cephalexin, all of the filamentous cells had divided into normal-size, motile cells of E. coli.

When grown in agarose microchambers, shaped, filamentous cells grew flagella randomly along their length (Figure 2c). We observed the flagella by fluorescently labeling the cell body and flagella with a cyanine monoester reactive dye. ${ }^{23}$ We collected video images of fluorescent, shaped, filamentous cells and analyzed the length and number of flagella for 24 cells; the cells were grown for $1.5 \mathrm{hr}$ in microchambers ( width $=2 \mu \mathrm{m}$, height $=2.5 \mu \mathrm{m}$, inner diameter $=10 \mu \mathrm{m}$ ). The average length of the cells was $13.7 \pm 2.7 \mu \mathrm{m}$ and the average number of flagella per cell was $13 \pm 3$ flagella. The average number of flagella per length was $1.0 \pm$ 0.2 flagella per $\mu \mathrm{m}$. Non-filamentous, motile cells of $E$. coli are $2-5 \mu \mathrm{m}$ long and typically have 1-2 flagella per $\mu \mathrm{m} .{ }^{23} \mathrm{We}$ examined the movement of shaped filamentous cells after their release from the chambers using phase-contrast video microscopy. Figure 5a shows superimposed, time-lapse images of a crescent-shaped cell slowly translating in solution; the translational velocity and rotational frequency of this cell was $6 \mu \mathrm{m} / \mathrm{s}$ and $0.8 \mathrm{~Hz}$, respectively. Figure $5 \mathrm{~b}$ shows superimposed, time-lapse images of the movement of a spiral cell with a small pitch immediately after its release from a microchamber; this cell had a translational velocity of $5 \mu \mathrm{m} / \mathrm{s}$. Cells with a larger spiral pitch were obtained by additional growth in solution after releasing spiral cells from microchambers. Figure $5 \mathrm{c}$ shows superimposed, time-lapse images of the movement of a spiral cell that had been released from a chamber and grown for $2 \mathrm{hr}$ at $25^{\circ} \mathrm{C}$ in growth media containing cephalexin; the translational velocity and rotational frequency of this cell was $15 \mu \mathrm{m} / \mathrm{s}$ and $1.5 \mathrm{~Hz}$, respectively.

In conclusion, this procedure provides a simple route to motile, filamentous cells of $E$. coli with defined shapes. The use of agarose microchambers for confining cells allows us to grow filamentous cells into shapes; the shapes of cells are retained after release from the microchambers into solution, and can be further modified by growth in solution in the presence of cephalexin. Our method predictably produces filamentous cells of $E$. coli with defined shapes; the diversity of shapes that can be made using this method exceeds the number of shapes that are available in nature or through genetic manipulation. We believe that these filamentous cells will be useful in examining the synthesis of peptidoglycan and its influence on cell shape, and the impact of mechanical stress on the growth of cells. We believe that this new technique may be useful for studying the biochemical components that determine the shape of cells, 24,25 and the efficiency of movement of cells with different shapes; these studies may provide insight into the evolution of the shape of bacteria found in nature. ${ }^{26}$ Finally, the confinement and study of cells of bacteria in agarose microchambers is not limited to filamentous cells of bacteria, and may be a useful technique for studying any type of single, isolated cells in a hydrated, nutritive environment.

\section{Supplementary Material}

Refer to Web version on PubMed Central for supplementary material.

\section{Acknowledgement}

This research was supported by the NIH (GM065364), and used the MRSEC shared facilities supported by the NSF under Award No. DMR-0213805. W. R. D. acknowledges a NSF-IGERT Biomechanics Training Grant (DGE-0221682). D. B. W. was a recipient of a postdoctoral fellowship from the National Institutes of Health (GM067445). We thank Dan Kahne and L. Mahadevan for helpful discussions, Linda Turner for helpful discussions about motility and fluorescent labeling, and Howard Berg for the gift of E. coli strain AW405.

\section{References}

(1). Weiss DS. Mol. Microbiol 2004;54:588-597. [PubMed: 15491352] 
(2). Arends SJR, Weiss DS. J. Bacteriol 2004;186:880-884. [PubMed: 14729718]

(3). Maki N, Gestwicki JE, Lake EM, Kiessling LL, Adler J. J. Bacteriol 2000;182:4337-4342. [PubMed: 10894745]

(4). Ishihara A, Segall JE, Block SM, Berg HC. J. Bacteriol 1983;155:228-237. [PubMed: 6345503]

(5). Segall JE, Ishihara A, Berg HC. J. Bacteriol 1985;161:51-59. [PubMed: 3881399]

(6). DePedro MA, Quintela JC, Holtje JV, Schwarz H. J. Bacteriol 1997;179:2823-2834. [PubMed: 9139895]

(7). Eberhardt C, Kuerschner L, Weiss DS. J. Bacteriol 2003;185:3726-3734. [PubMed: 12813065]

(8). Berg, HC. E. coli in Motion. Springer-Verlag; New York: 2004.

(9). Lowe G, Meister M, Berg HC. Nature 1987;325:637-640.

(10). Weiss DS, Chen JC, Ghigo JM, Boyd D, Beckwith J. J. Bacteriol 1999;181:508-520. [PubMed: 9882665]

(11). Denome SA, Elf PK, Henderson TA, Nelson DE, Young KD. J. Bacteriol 1999;181:3981-3993. [PubMed: 10383966]

(12). Nelson DE, Young KD. J. Bacteriol 2000;182:1714-1721. [PubMed: 10692378]

(13). Popham DL, Young KD. Current Opinion in Microbiology 2003;6:594-599. [PubMed: 14662355]

(14). Jones LJF, Carballido-Lopez R, Errington J. Cell 2001;104:913-922. [PubMed: 11290328]

(15). Wachi M, Doi M, Tamaki S, Park W, Nakajimaiijima S, Matsuhashi M. Journal of Bacteriology 1987;169:4935-4940. [PubMed: 2822655]

(16). Varma A, Young KD. J. Bacteriol 2004;186:6768-6774. [PubMed: 15466028]

(17). Akerlund T, Nordstrom K, Bernander R. Molecular Microbiology 1993;10:849-858. [PubMed: 7934847]

(18). Rondelez Y, Tresset G, Nakashima T, Kato-Yamada Y, Fujita H, Takeuchi S, Noji H. Nature 2005;433:773-777. [PubMed: 15716957]

(19). Rondelez Y, Tresset G, Tabata KV, Arata H, Fujita H, Takeuchi S, Noji H. Nature Biotech 2005;23:361-365.

(20). Xia Y, Whitesides GM. Angew. Chem. Int. Ed. Engl 1998;37:550-575.

(21). Armstrong JB, Adler J, Dahl MM. J. Bacteriol 1967;93:390-398. [PubMed: 5335897]

(22). Neidhardt, Frederick C., et al., editors. Escherichia coli and Salmonella: Cellular and Molecular Biology. 2nd ed.. 2. ASM Press; Washington, DC: 1996.

(23). Turner L, Ryu WS, Berg HC. J. Bacteriol 2000;182:2793-2801. [PubMed: 10781548]

(24). Young KD. Mol. Microbiol 2003;49:571-580. [PubMed: 12914007]

(25). Ausmees N, Kuhn JR, Jacobs-Wagner C. Cell 2003;115:705-713. [PubMed: 14675535]

(26). Dusenbery DB. J. Bacteriol 1998;180:5978-5983. [PubMed: 9811657] 
(a)

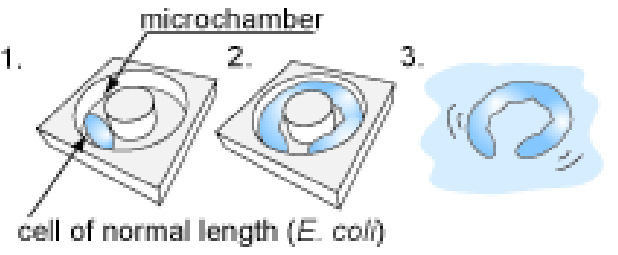

(b)

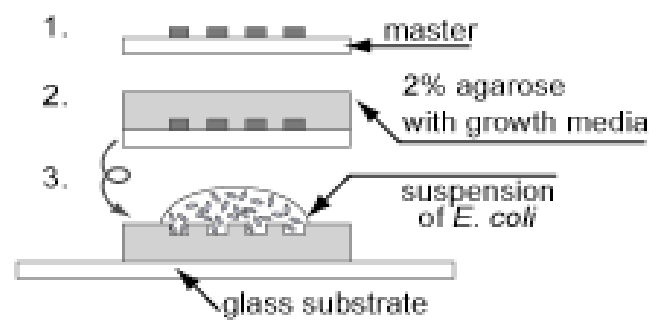

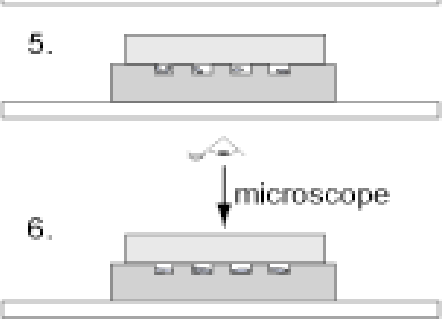

(c)
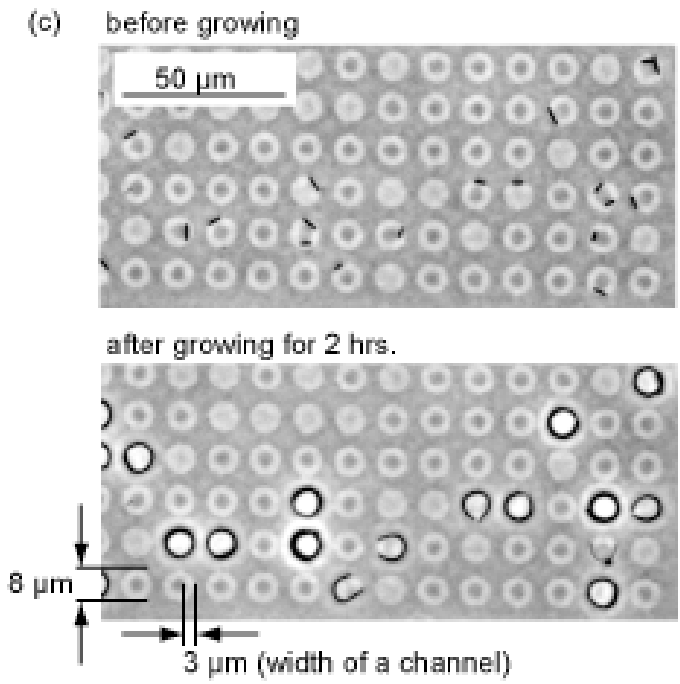

Figure 1.

(a) A schematic representation of the method for controlling the shape of filamentous $E$. coli cells. 1) Cells were confined in a microchamber (1.5-2.5 $\mu \mathrm{m}$ deep and 2-20 $\mu \mathrm{m}$ wide) fabricated in agarose containing growth media (TB broth, $0.05 \%$ BSA, and $20 \mu \mathrm{g} / \mathrm{mL}$ cephalexin); 2) Cells grew into a filamentous phenotype in the presence of cephalexin; 3) Cells confined in chambers were released into solution. (b) A schematic representation depicting the approach for confining cells in microchambers. 1) A master was fabricated in photoresist (SU8) using photolithography; 2$)$ Hot growth media $\left(65^{\circ} \mathrm{C}\right)$ containing $2 \%$ agarose was poured onto the master or a PDMS replica and allowed to gel. 3) The agarose gel containing imprinted chambers was peeled away from the master and seeded with cells of E. coli. 4) An agarose slab (0.5\% 
w/v) or a thin PDMS film ( $150 \mu \mathrm{m}$ thick) was placed on top of the suspension of cells to provide the ceiling for the chambers. 5) Cells were grown for $1-3 \mathrm{hr}$ at $33^{\circ} \mathrm{C}$. 6) Cells were imaged using phase-contrast microscopy. (c) An image of donut-shaped microchambers before the growth of filamentous cells of $E$. coli, and after; the chambers had the following dimensions: height $=2.2 \mu \mathrm{m}$, diameter $=8 \mu \mathrm{m}$, width of channel $=2 \mu \mathrm{m}$, and pitch $=10 \mu \mathrm{m}$. The images were not modified in any way; bright halos around the cells are due to phase contrast imaging. 


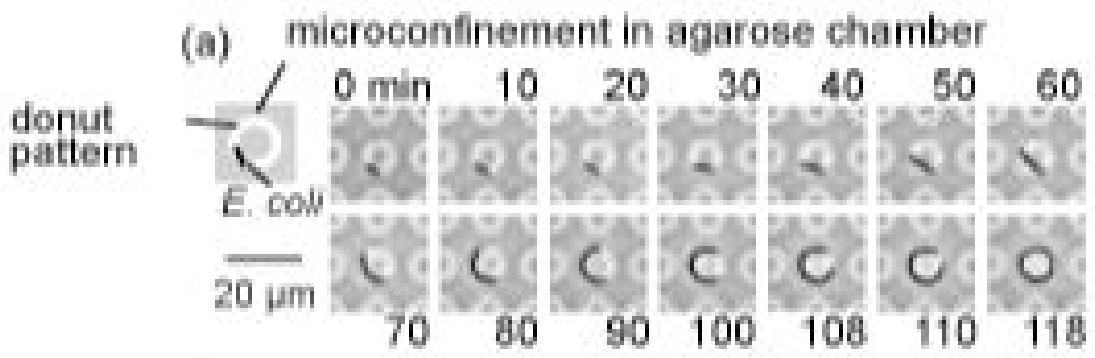

(b)

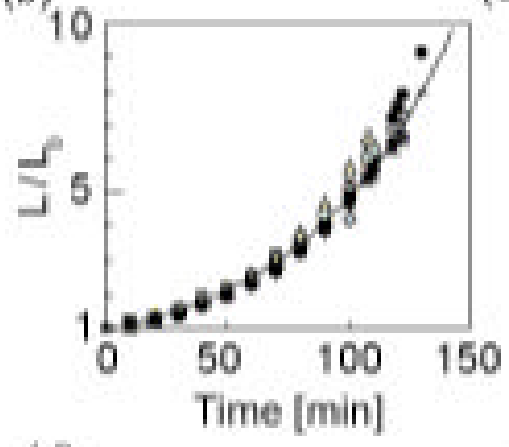

(d)

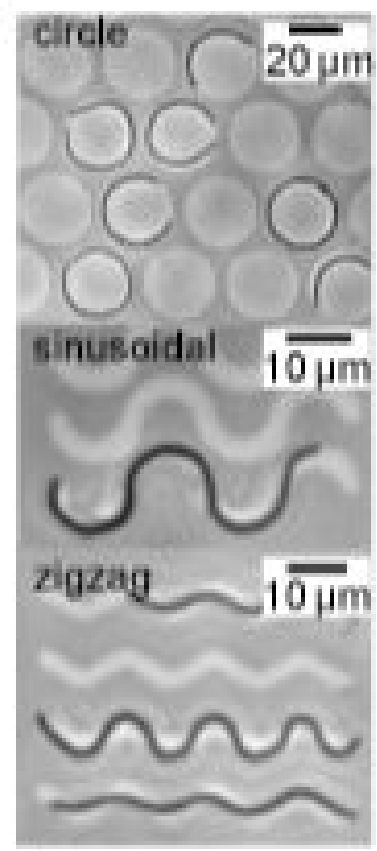

(c)

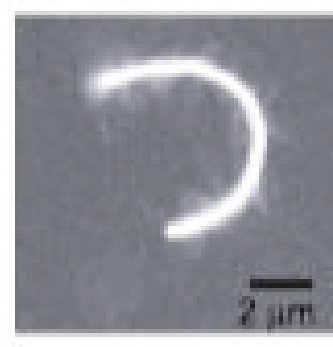

(e)

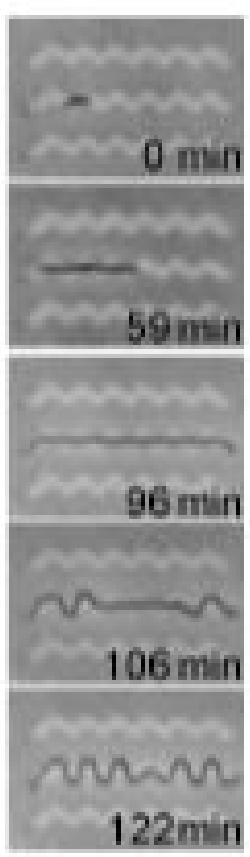

Figure 2.

(a) Sequential images depicting the growth of a filamentous cell in a donut-shaped chamber over time (diameter $=10 \mu \mathrm{m}$, width of channel $=2 \mu \mathrm{m}$, height $=1.5 \mu \mathrm{m}$ ) at $32^{\circ} \mathrm{C}$. (b) A plot of the rate of growth (the ratio of the length (L) to the initial length (Lo))of 14 filamentous cells grown in these chambers over time. The line shows the fit of the data to the equation, $\mathrm{L} / \mathrm{L}_{\mathrm{o}}=$ $2^{t / \tau}$, where $t$ is the time in minutes and $\tau$ is the "doubling time"in minutes (the time required for cells to double in length). The length of cells increased exponentially to 8 times their initial length after $2 \mathrm{hr}$; by fitting each curve separately, we calculated the doubling time, $\tau$, to be 41 \pm 4 min. (c) A fluorescent image of a crescent-shaped filamentous cell that was grown in a microchamber for $100 \mathrm{~min}$, then released and labeled with cyanine dye, Сy3; shaped, 
filamentous cells contained flagella along the length of the cell. (d) Phase-contrast images of circular, sinusoidal, and zigzag filamentous cells in microchambers. (e) Time-lapse phasecontrast images of a filamentous cell of $E$. coli growing in a zigzag-shaped chamber. 
(a)

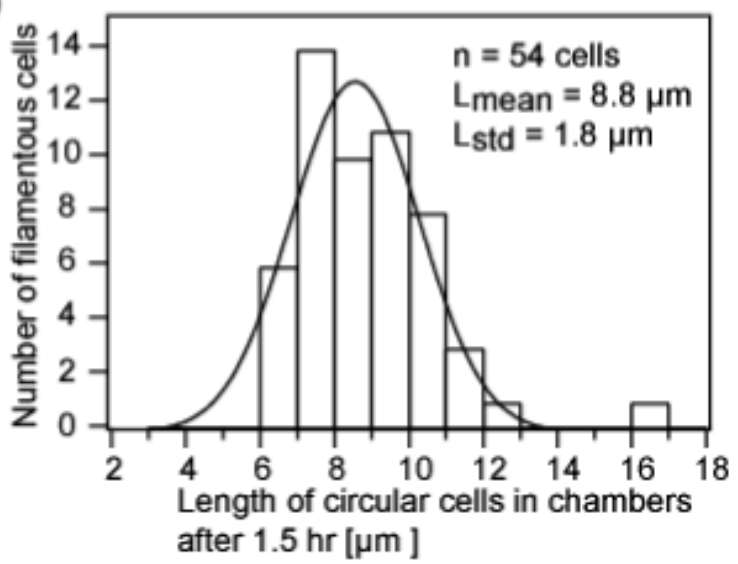

(b)

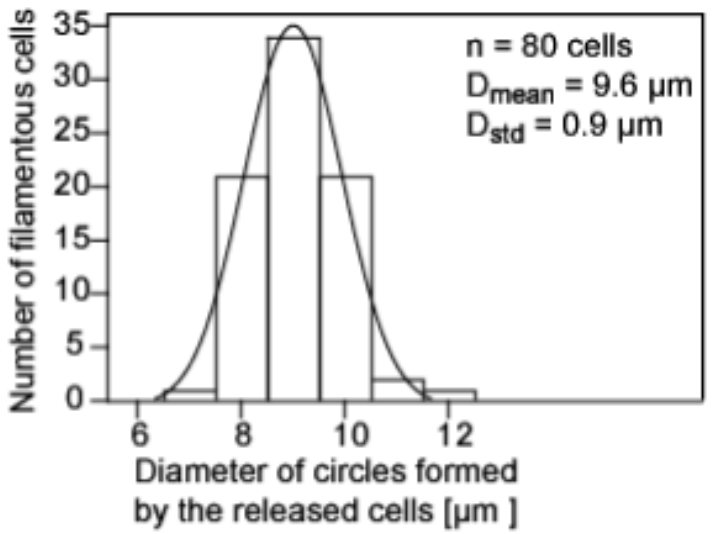

(c)

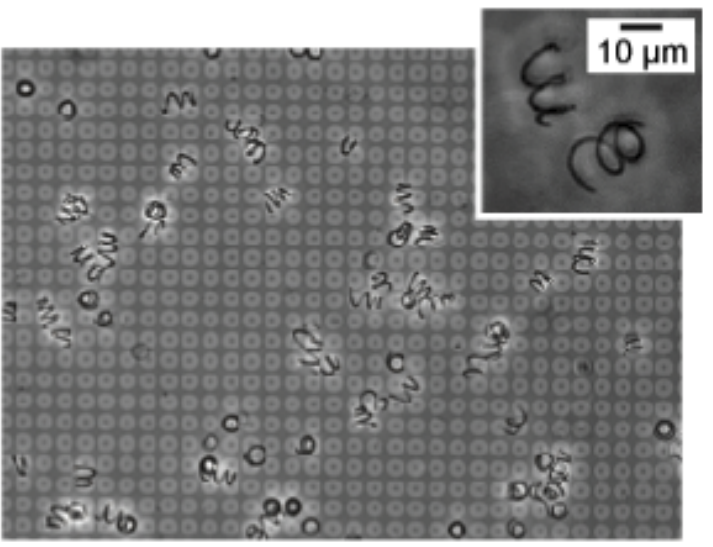

Figure 3.

(a) The distribution of sizes of circular cells grown within donut-shaped microchambers for $1.5 \mathrm{hr}$; dimensions as in Figure 2. (b) The distribution in the diameter of the circle of circular cells after their release from the chambers. (c) Phase-contrast microscopy image of spiral, filamentous cells against a background of agarose microchambers; the image inset shows spiral cells at a higher magnification. The microchambers used in this experiment had the following dimensions: diameter of the inner circle $=4 \mu \mathrm{m}$, diameter of the outer circle $=13 \mu \mathrm{m}$, and height $=2 \mu \mathrm{m}$. 
(a)

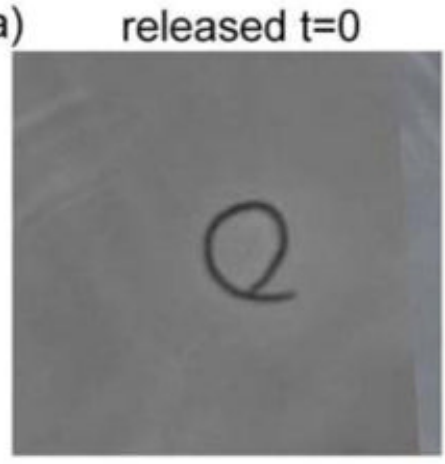

(b) released $\mathrm{t}=0$

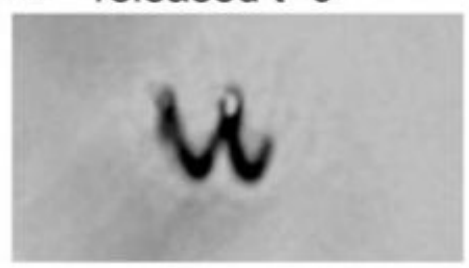

(c) released $\mathrm{t}=0$

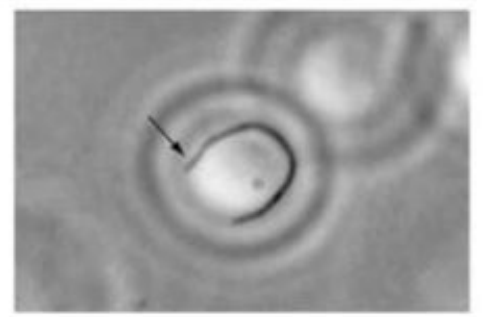

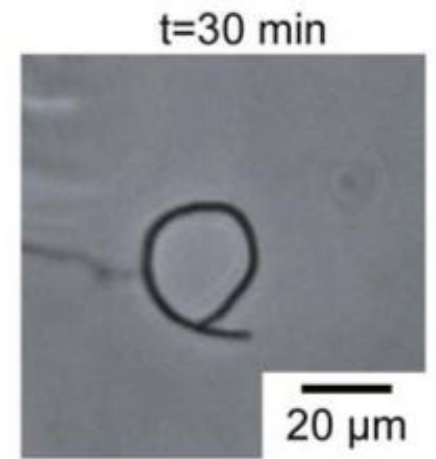

$\mathrm{t}=45 \mathrm{~min}$

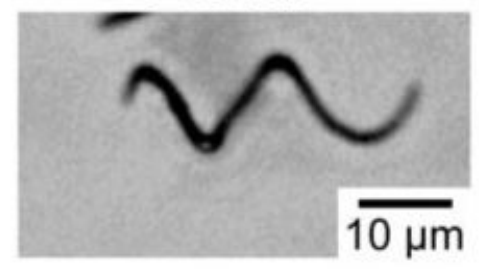

$t=30$ min

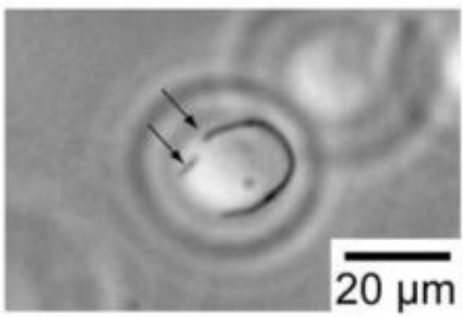

Figure 4.

(a) Time-lapse images of a circular cell released into growth media containing cephalexin; this series of images illustrates that the cell retains its shape, but grows uniformly. (b) Time-lapse images of a spiral cell released into growth media containing cephalexin, illustrating that the pitch of the helix increases over time. (c) A crescent-shaped cell divides after release into growth media without cephalexin. Cells were imaged using phase-contrast microscopy. 
(a)

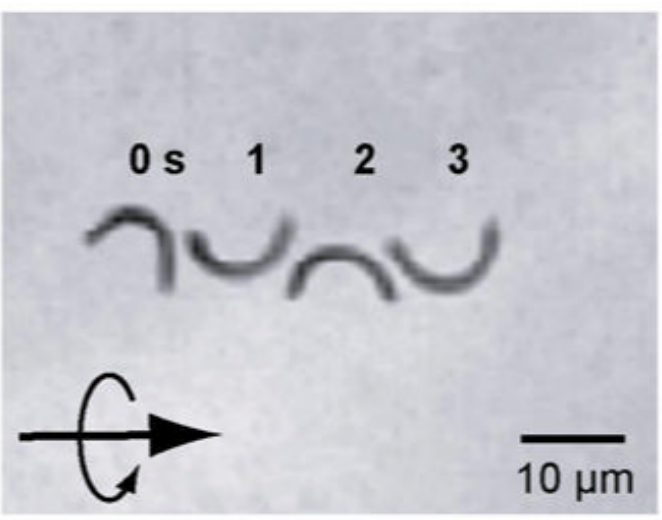

(b)

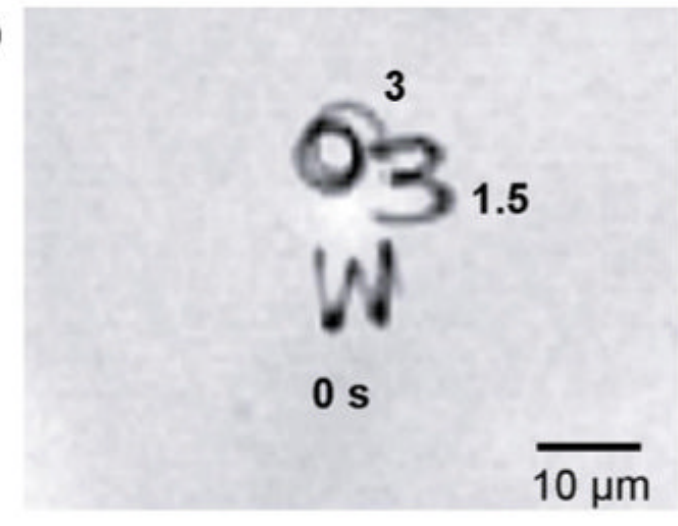

(c)

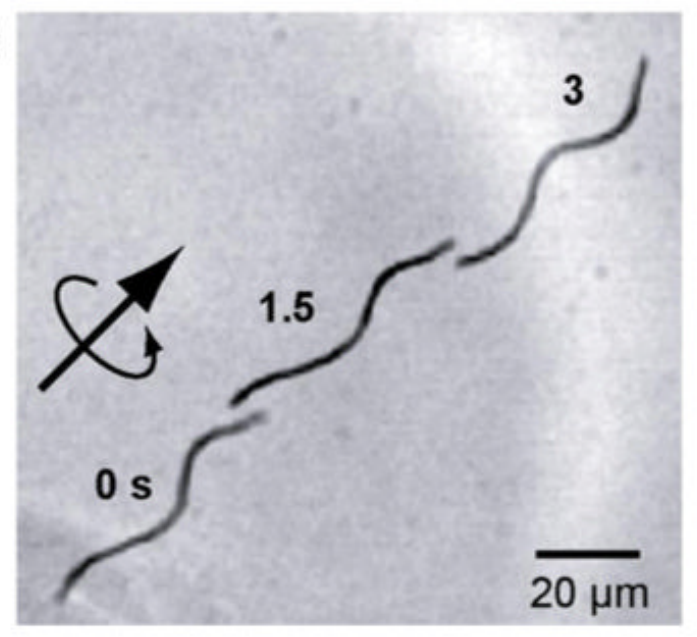

Figure 5.

(a) Superimposed time-lapse images showing the motion of a crescent-shaped cell swimming immediately after its release into solution. (b) Superimposed time-lapse images showing the motion of a spiral-shaped cell swimming immediately after its release into solution; the cell had grown in a donut-shaped chamber for $2 \mathrm{hr}$. (c) Superimposed time-lapse images showing the translational motion of the spiral cell from (b) after growth for an additional $2 \mathrm{hr}$ in solution. All cells were released into TB broth ( $1 \%$ tryptone, $0.5 \%$ sodium chloride) containing $0.5 \%$ BSA and $20 \mu \mathrm{g} / \mathrm{mL}$ cephalexin. Cells were imaged using phase-contrast video microscopy. 